EXTENDED REPORT

\title{
First line treatment of knee osteoarthritis in outpatients in France: adherence to the EULAR 2000 recommendations and factors influencing adherence
}

\author{
L Denoeud, B Mazières, C Payen-Champenois, P Ravaud
}

Ann Rheum Dis 2005;64:70-74. doi: 10.1136/ard.2003.015263

See end of article for authors' affiliations

......................

Correspondence to: Dr Philippe Ravaud Département d'Epidémiologie, Biostatistique et Recherche Clinique, Hôpital BichatClaude Bernard, 46 rue Henri Huchard, 75018

Paris, France;

philippe.ravaud@

bch.ap-hop-paris.fr

Accepted 11 July 2004

\begin{abstract}
Objectives: To document adherence to two parts of the EULAR 2000 recommendations for knee osteoarthritis, concerning non-pharmacological and pharmacological first line management; and to identify factors influencing adherence to the recommendations.

Methods: In a prospective study, 1030 randomly selected French general practitioners completed questionnaires about three unselected outpatients with osteoarthritis, and about their own practice, knowledge, and agreement with the EULAR 2000 recommendations. Percentages of adherence of their prescriptions to both parts of the recommendation were calculated, and probabilities of non-adherence analysed in relation to patient and physician related characteristics, using multilevel logistic regression analysis.

Results: Data were obtained from 967 physicians and 2430 patients. The EULAR 2000 recommendations were familiar to $79 \%$ of the GPs; $99 \%$ agreed with the non-pharmacological part and $97 \%$ with the pharmacological part. Adherence to the two parts was $74.8 \%$ and $73.6 \%$, but $54.2 \%$ for both together. Factors increasing adherence to the non-pharmacological recommendation were patient body mass index $>35 \mathrm{~kg} / \mathrm{m}^{2}$ (odds ratio 0.11 (95\% confidence interval, 0.06 to 0.21 )), patient's stated preference for a treatment (OR $0.43(0.55$ to 0.97$)$ ), and physician's regular continuance of medical education (OR 0.76 (0.59 to 0.98)); patient's age and duration of symptoms decreased adherence. Factors increasing adherence to the pharmacological recommendation were gastrointestinal disease (OR 0.5010 .35 to $0.72)$ ) and physician's knowledge of the EULAR recommendations (OR 0.75 (0.60 to 0.93$)$ ).

Conclusions: Although most physicians agreed with the EULAR 2000 recommendations, adherence was only approximately $75 \%$ for each of the non-pharmacological and pharmacological recommendations and $54 \%$ for both together.
\end{abstract}

O steoarthritis is a major source of morbidity, disability, and loss of function, especially in elderly people, and can result in severely impaired quality of life in patients with persisting disease. ${ }^{1}$ Because of a rapid increase in the number of people older than 55 years in Western countries, knee osteoarthritis is a growing public health problem.

Recommendations for management of knee osteoarthritis were developed in 2000 by the American College of Rheumatology $(\mathrm{ACR})^{2}$ and the European League Against Rheumatism (EULAR ${ }^{3}$ These recommendations, which particularly concern pharmacological and non-pharmacological first line therapeutic management of outpatients with knee osteoarthritis, are expected to be useful in improving practice. Nevertheless, difficulties with the implementation of recommendations have been well documented in many medical fields. ${ }^{4}$ Non-adherence might be related to physician factors, such as lack of knowledge of the recommendations or partial disagreement with their content, but also to patient factors such as age, sex, and perceptions and expectations of care. Specific barriers to physician adherence to recommendations regarding osteoarthritis are not known.

Our aims in this prospective survey were, first, to document adherence to the EULAR 2000 recommendations about first line non-pharmacological and pharmacological therapeutic management of knee osteoarthritis in general practice in France, and second, to identify factors influencing adherence to these recommendations.

\section{METHODS}

Design

This was a prospective, observational, multicentre survey conducted in France. Data were collected between September 2001 and March 2002.

\section{Recruitment}

A representative sample of 1030 general practitioners (GPs) was randomly selected from a database listing all GPs in France, taking into considerations the proportion of GPs from each French region. We expected to include 1000 GPs in the survey, assuming that the non-response rate would be 3\%.

Each physician was asked to include their first three consecutive outpatients with painful knee osteoarthritis seen during eight weeks of normal medical practice, who had not received pharmacological treatment for the condition during the past six months (patients taking self medication could be included). In addition, the patients had to fulfil the clinical and radiological ACR criteria for knee osteoarthritis. ${ }^{5}$

\section{Data collection}

The GPs were asked to complete questionnaires concerning the patients' date of inclusion in the survey, their demographic characteristics, their osteoarthritis (localisation, duration of symptoms, and symptom severity-for example,

Abbreviations: ACR, American College of Rheumatology; EULAR, European League Against Rheumatism; NSAID, non-steroidal antiinflammatory drug 
night pain, morning stiffness, joint effusions, level of pain), any associated abnormalities and treatments, their stated preferences for a treatment, and any non-pharmacological and pharmacological treatments prescribed.

In addition, after the inclusion of the three patients, each physician received a questionnaire concerning their age and date of graduation from medical school, professional activity (for example, degree of urbanisation of the city of practice, the number of consultations per week, continuing medical education received), and their beliefs about the recommendations (knowledge of the EULAR 2000 recommendations for knee osteoarthritis, whether the physician agreed with these recommendations, and reasons for disagreement or lack of intention to apply them). Physicians who had not returned their questionnaires were excluded from the survey, as were the patients they had seen.

\section{Outcome measures}

Two key features of the EULAR 2000 recommendations were used to assess adherence to the recommendations. One concerned non-pharmacological treatment:

\begin{abstract}
"Optimal management of knee osteoarthritis requires a combination of pharmacological and non-pharmacological treatment modalities. Non-pharmacological treatment of knee osteoarthritis should include regular education, exercise, appliances (sticks, insoles), and weight reduction."
\end{abstract}

The other concerned first line pharmacological treatment:

\begin{abstract}
"Paracetamol (acetaminophen) is the oral analgesic to try first and, if successful, is the preferred long term analgesic. Non-steroidal anti-inflammatory drugs (NSAIDs) should be considered in patients (with effusion) unresponsive to paracetamol."
\end{abstract}

Treatments prescribed at the end of the consultation allowed for calculating the degree of adherence to the recommendations, divided into two parts (A, non-pharmacological treatment; B, pharmacological treatment), and the degree of implementation of both parts simultaneously. Recommendation A was adhered to if the physician prescribed a non-pharmacological treatment; recommendation B was adhered to if the physician prescribed paracetamol only or NSAIDs when the patient's symptoms increased (increased disease was defined as joint effusion with or without pain increase by more than $50 \%$ within less than a week, night pain, and morning stiffness for longer than 45 minutes).

We also determined the proportion of physicians who agreed with the recommendations' contents, and the reasons for non-agreement or for lack of desire to follow the recommendations even if the physician agreed with them.

\section{Statistical analysis}

Statistical analysis was carried out using the SAS system, version 8-12 (SAS Institute, Cary, North Carolina, USA).

Adherence to the EULAR 2000 recommendations and the choice of analgesic drug were studied in relation to patient and physician related characteristics simultaneously, using multilevel logistic regression analysis. We aimed to consider simultaneously 20 variables concerning patient characteristics and 15 concerning physician characteristics. Thus 1000 physicians and 3000 patients were needed. Multivariate analysis was preceded by univariate analysis and correlation screening. Variables where the $\beta$ value was less than $10 \%$ were kept in the final logistic regression model.
The likelihood of dependent variables is presented as odds ratios (ORs) with 95\% confidence intervals (CI).

\section{RESULTS}

\section{Patient and physician characteristics}

In all, 972 physicians agreed to participate in the survey; five of these did not return their questionnaires. Valid data were thus obtained from 967 physicians, who had seen 2916 patients. Nevertheless, 486 did not meet the inclusion criteria, so 2430 patients were considered in the analysis. The mean number of patients per physician was 2.5. The mean age of the physicians was 47.1 years; $61.0 \%$ practised in small cities (less than 30000 inhabitants), and most (79.5\%) consulted more than 100 patients a week. The main patient characteristics are given in table 1 .

\section{Knowledge of recommendations and agreement}

Seventy nine per cent of the physicians $(n=762)$ reported that they knew of the EULAR 2000 recommendations.

\section{Recommendation A (non-pharmacological treatment)}

Ninety nine per cent of the physicians $(\mathrm{n}=954)$ agreed with recommendation $\mathrm{A}$; only $1.1 \% \quad(\mathrm{n}=11)$ disagreed (five disagreed with recommendations in general and seven with this particular one). Among the 954 physicians who agreed with the recommendation, $97 \%(\mathrm{n}=924)$ intended to apply them, and $3 \%(n=30)$ did not ( 12 because of lack of time, 17 because the recommendations did not consider the patient's opinion, 21 found them too rigid, and seven thought they contradicted information provided by the pharmaceutical industry).

Recommendation B (pharmacological treatment) Ninety seven per cent of the physicians $(n=927)$ agreed with recommendation B. Only $3.4 \%(\mathrm{n}=33)$ disagreed: $2.3 \%$ $(\mathrm{n}=22)$ disagreed with recommendations in general, and $2.2 \%(\mathrm{n}=21)$ disagreed with this particular one because they did not normally follow this treatment in their practice $(n=17)$, they lacked confidence in the developer of the

Table 1 Patient characteristics $(n=2430)$

\begin{tabular}{ll}
\hline Age (years) & $66.8(10.6)$ \\
Men (\%) & 43.2 \\
Weight (kg) & $77.6(13.9)$ \\
BMI (kg/ ${ }^{2}$ ) & $28.0(4.5)$ \\
Duration of symptoms (years) & $4.6(5.8)$ \\
Pain intensity (VAS) & $62.1(10.4)$ \\
Increased symptoms of osteoarthritis* (\%) & 27.4 \\
& \\
Associated diseases (\%) & \\
Gastrointestinal & 9.5 \\
Heart & 31.5 \\
Kidney & 0.7 \\
& \\
Associated treatment (\%) & 74.7 \\
Cardiovascular system & 60.6 \\
Alimentary tract and metabolism & 15.3 \\
Nervous system & 11.6 \\
Blood and blood forming organs & 8.4 \\
Genitourinary system & 4.1 \\
Respiratory system & 3.4 \\
& \\
Contraindications (\%) & 19.9 \\
For NSAIDs & \\
For paracetamol & \\
\hline Values are mean (SD) or per cent. & \\
*Increased symptoms of osteoarthritis were defined as knee effusion with \\
or without pain increase+pain at night+morning stiffness for more than \\
45 minutes. \\
BMl, body mass index; NSAID, non-steroidal anti-inflammatory drug; \\
VAS, visual analogue scale. \\
$\quad$
\end{tabular}


Table 2 Pharmacological treatment prescribed $(n=2430)$

\begin{tabular}{ll}
\hline Treatment & Per cent (range) \\
\hline $\begin{array}{l}\text { Paracetamol } \\
\text { Median daily frequency of administration }\end{array}$ & 95.8 \\
Median daily dose (g) & $4(1$ to 6) 6$)$ \\
Median duration of prescription (d) & $15(2$ to 200) \\
NSAID & 34.2 \\
Median duration of the prescription of classical & \\
NSAIDs (d) & 10 \\
Median duration of the prescription of COX2 & \\
inhibitors* (d) & 29.6 \\
Prescription for effusion and/or 3 other symptoms \\
of increased osteoarthritis
\end{tabular}

*COX2 inhibitors: cyclo-oxygenase selective non-steroidal antiinflammatory drugs.

NSAID, non-steroidal anti-inflammatory drug.

recommendation $(n=7)$, they thought the recommendation contradicted information provided by the pharmaceutical industry $(\mathrm{n}=8)$, or they knew of contradictory recommendations $(\mathrm{n}=8)$.

Among the 927 physicians who agreed with the recommendation, $99 \%(n=915)$ intended to apply them and 12 did not (two because of lack of time, five because the recommendations did not consider the patient's opinion, 11 found them too rigid, and two thought they contradicted information delivered by the pharmaceutical industry).

\section{Adherence to the recommendations}

For $74.8 \%$ of the cases, physicians prescribed non-pharmacological treatments (weight reduction 58.7\%; physical exercise $48.7 \%$; insoles $5.2 \%$ ).

Table 2 shows pharmacological treatments prescribed as first line treatment for knee osteoarthritis: $95.8 \%$ of the patients received paracetamol (60.6\% paracetamol alone) and $34.2 \%$ received NSAIDs. NSAIDs were prescribed for $47.0 \%$ of the patients with effusion or other signs of increased disease and for $29.7 \%$ of the patients without increased disease.

Thus the percentage of adherence to recommendation A was $74.8 \%$ (that is, $74.8 \%$ of the patients received at least one of the non-pharmacological treatments). The percentage of adherence to recommendation B was $73.6 \%(73.6 \%$ of the patients received paracetamol or, in the case of increased disease, NSAIDs). The percentage of adherence to both recommendations together was $54.2 \%$.

\section{Factors influencing adherence to the recommendations}

Table 3 shows odds ratios for non-adherence to recommendation A. The probability of non-adherence increased with the patient's age $(p<0.001$ for patients older than 75 years $)$ and with the duration of symptoms $(p=0.02)$. Factors otherwise increasing adherence were the patient's weight $\left(\mathrm{p}<0.001\right.$ for body mass index (BMI) of $25 \mathrm{~kg} / \mathrm{m}^{2}$ or greater), patient's stated preferences for a particular treatment $(p=0.03)$, regular continuance of medical education by the physician $(\mathrm{p}=0.04)$, and time since the physician graduated from medical school $(\mathrm{p}<0.001)$. Physicians' knowledge of the EULAR 2000 recommendations did not influence their

Table 3 Relation between patient and physician characteristics and non-adherence to EULAR 2000 non-pharmacological recommendation*

\begin{tabular}{|c|c|c|}
\hline Variable & Odds ratio $(95 \% \mathrm{Cl}) \dagger$ & n (\%) \\
\hline Variables related to patients & & $(n=2430)$ \\
\hline \multicolumn{3}{|l|}{ Age (years) } \\
\hline$<60$ & 1 & $647(26.6)$ \\
\hline $61-65$ & 1.08 (0.74 to 1.57$)$ & $366(15.1)$ \\
\hline $66-70$ & 1.46 (1.04 to 2.04$)$ & $453(18.7)$ \\
\hline \multirow[t]{2}{*}{$71-75$} & $1.66(1.19$ to 2.31$)$ & $480(19.8)$ \\
\hline & $3.20(2.29$ to 4.46$)$ & $483(19.9)$ \\
\hline \multicolumn{3}{|l|}{ BMI $\left(\mathrm{kg} / \mathrm{m}^{2}\right)$} \\
\hline$<25$ & 1 & $602(24.9)$ \\
\hline $25-30$ & $0.36(0.28$ to 0.45$)$ & $1168(48.3)$ \\
\hline $30-35$ & $0.15(0.11$ to 0.22$)$ & $480(19.9)$ \\
\hline$\geqslant 35$ & $0.11(0.06$ to 0.21$)$ & $167(6.9)$ \\
\hline Duration of symptoms & $1.02(1.01$ to 1.04$)$ & - \\
\hline \multicolumn{3}{|l|}{ Heart disease } \\
\hline No & 1 & $1665(68.6)$ \\
\hline Yes & $0.69(0.54$ to 0.88$)$ & $764(31.4)$ \\
\hline \multicolumn{3}{|l|}{ Patient's stated preferences for a treatment } \\
\hline No & 1 & $1962(81.8)$ \\
\hline Yes & $0.43(0.55$ to 0.97$)$ & $436(18.2)$ \\
\hline Variables related to physicians & & $(n=967)$ \\
\hline Time since graduation from medical school & $0.98(0.96$ to 0.99$)$ & - \\
\hline \multicolumn{3}{|l|}{ Regular continuing medical education } \\
\hline No & 1 & $200(20.8)$ \\
\hline Yes & $0.76(0.59$ to 0.98$)$ & $762(79.2)$ \\
\hline \multicolumn{3}{|c|}{$\begin{array}{l}\text { "Optimal management of knee osteoarthritis requires a combination of pharmacological and non- } \\
\text { pharmacological treatment modalities. Non-pharmacological treatment of knee osteoarthritis should include } \\
\text { regular education, exercise, appliances (sticks, insoles), and weight reduction." } \\
\text { †Multilevel regression logistic model representing probabilities of non-adherence as odds ratios with } 95 \% \\
\text { confidence intervals ( } n=2111 \text { ). An odds ratio }>1 \text { means a higher probability of non-adherence to the } \\
\text { recommendation. } \\
\mathrm{Cl} \text {, confidence interval; BMl, body mass index. }\end{array}$} \\
\hline
\end{tabular}




\begin{tabular}{|c|c|c|}
\hline Variable & Odds ratio $(95 \% \mathrm{Cl}) \dagger$ & $n(\%)$ \\
\hline \multicolumn{3}{|l|}{$\begin{array}{l}\text { Variables related to patients } \\
\mathrm{BMI}\left(\mathrm{kg} / \mathrm{m}^{2}\right)\end{array}$} \\
\hline $\begin{array}{l}<25 \\
<25 / 1\end{array}$ & 1 & $602(24.9)$ \\
\hline $25-30$ & 0.95 (0.75 to 1.20$)$ & 1168 (48.3) \\
\hline $30-35$ & $1.13(0.86$ to 1.50$)$ & 480 (19.() \\
\hline$\geqslant 35$ & $1.54(1.05$ to 2.25$)$ & $167(6.9)$ \\
\hline \multicolumn{3}{|l|}{ Gastrointestinal disease } \\
\hline No & 1 & $2199(90.5)$ \\
\hline Yes & 0.50 (0.35 to 0.72$)$ & $231(9.5)$ \\
\hline Variables related to physicians & & $(n=967)$ \\
\hline Time since graduation from medical school & 0.98 (0.97 to 0.99 ) & - \\
\hline \multicolumn{3}{|l|}{ Knowledge of the EULAR 2000 recommendations } \\
\hline No & 1 & $202(21.0)$ \\
\hline Yes & 0.75 (0.60 to 0.93 ) & $762(79.1)$ \\
\hline
\end{tabular}

*"Paracetamol is the oral analgesic to try first and, if successful, is the preferred long term analgesic. NSAIDs should be considered in patients (with effusion) unresponsive to paracetamol".

†Multilevel regression logistic model representing probabilities of non-adherence as odds ratios with $95 \%$

confidence intervals $(n=2357)$. An odds ratio $>1$ means a higher probability of non-adherence to the recommendation.

BMI, body mass index; Cl, confidence interval; NSAID, non-steroidal anti-inflammatory drug.

adherence to the recommendation for non-pharmacological treatments.

Table 4 shows odds rations for non-adherence to recommendation B. Adherence was affected by patient's BMI of $35 \mathrm{~kg} / \mathrm{m}^{2}$ or more $(\mathrm{p}=0.03)$. Physicians were about twice as likely to adhere to recommendation $\mathrm{B}$ if patients had a gastrointestinal disease $(p<0.001)$. Adherence was also affected by the time since the physician graduated from medical school $(p=0.007)$ and knowledge of the EULAR 2000 recommendations $(\mathrm{p}=0.01)$.

\section{Factors influencing the choice of analgesic drug}

Table 5 shows odds ratios for the physician's choice of analgesic drug (paracetamol or NSAID) for first line treatment. Patients receiving associated analgesics were not considered in this analysis. The probability of receiving paracetamol increased with the duration of symptoms $(p=0.03)$ and with increased activity of the physician $(\mathrm{p}=0.04$ for more than 100 consultations a week). Patients were less likely to receive paracetamol if they had kidney disease $(p=0.01)$, if they stated preferences for a treatment $(p=0.03)$, or if the city of practice of the physician was large (population between 30000 and $100000 ; p=0.005$ ). Knowledge of the EULAR 2000 recommendations increased the likelihood of the physician prescribing paracetamol $(\mathrm{p}=0.01)$.

In all, $18 \%$ of patients stated a preference for treatment. When a preference was stated, it was for a specific product in $49.3 \%$ of cases and for a dosage form in $25 \%$. Safety concerns were expressed more often (in $11 \%$ of cases) than efficacy concerns $(2.9 \%)$.

\section{DISCUSSION}

Seventy nine per cent of the GPs in France knew of the EULAR 2000 recommendations for knee osteoarthritis before the beginning of the study. Although most (at least 97\%) agreed with the recommendations and intended to apply them, their adherence to the recommendations concerning both non-pharmacological and pharmacological treatment was only $54.2 \%$.

Time since the physician graduated from medical school was found to increase adherence to both parts of the EULAR

Table 5 Relation between patient and physician characteristics and the physician's choosing to prescribe paracetamol rather than NSAIDs or other analgesics

\begin{tabular}{|c|c|c|}
\hline Variable & Odds ratio $(95 \% \mathrm{Cl}) \dagger$ & n (\%) \\
\hline Variables related to patients & & $(n=2430)$ \\
\hline Duration of symptoms & 1.05 (1.01 to 1.10$)$ & \\
\hline \multicolumn{3}{|l|}{ Kidney disease } \\
\hline No & 1 & $2413(99.30)$ \\
\hline Yes & $0.17(0.04$ to 0.68$)$ & $17(0.70)$ \\
\hline \multicolumn{3}{|l|}{ Patient's stated preferences for a treatment } \\
\hline No & 1 & $1962(81.82)$ \\
\hline Yes & 0.56 (0.33 to 0.94$)$ & $436(18.18)$ \\
\hline Variables related to physicians & & $(n=967)$ \\
\hline \multicolumn{3}{|l|}{ Number of consultations per week } \\
\hline$\leqslant 100$ & 1 & $197(19.52)$ \\
\hline$>100$ & $1.68(1.02$ to 2.76$)$ & $763(79.48)$ \\
\hline \multicolumn{3}{|l|}{ Number of citizens in the city of practice } \\
\hline$<30000$ & 1 & $584(61.02)$ \\
\hline $30000-100000$ & $0.48(0.29$ to 0.80$)$ & $210(21.94)$ \\
\hline$>100000$ & $0.91(0.48$ to 1.73$)$ & $163(17.03)$ \\
\hline Knowledge of the EULAR 2000 recommendations & $1.92(1.17$ to 3.16$)$ & $762(79.05)$ \\
\hline
\end{tabular}


2000 recommendations. It is interesting that older physicians were also the ones who implemented the recommendations best. This is surprising if we are to assume that older physicians are less used to referring to recommendations than younger ones, and it contradicts the results of previous studies on adherence to recommendations. ${ }^{6}$ Knowledge of the EULAR 2000 recommendations was found to be a predictor of adherence to recommendation $\mathrm{B}$ rather than to recommendation A; non-pharmacological treatments were prescribed as often as they are in regular practice, regardless of whether the physician knew that these prescriptions were recommended by EULAR.

There are several limitations to our study. First, we chose not to explore adherence to all the EULAR 2000 recommendations, but only to the parts concerning first line pharmacological treatment (paracetamol and NSAIDs) and non-pharmacological prescriptions. The EULAR 2004 recommendations did not differ from the 2000 recommendations on these two points. ${ }^{7}$ Adherence to the other parts concerning, for example, intra-articular injections, symptomatic slow acting drugs, or joint replacement was not investigated. Second, answers to questions were self reported and this may have led to an idealised version of practice behaviour. Finally, we have highlighted some well known difficulties with the implementation of the recommendations-such as patients' preferences for treatments or non-controversial factors relating to non-adherence. Patients' preferences for treatments were the only part of patient attitudes explored during the study. Indeed, questionnaires were completed by GPs and not by the patients.

We observed well known differences between knowledge of the recommendations, agreement with them, and adherence to them in our study. This gap has been documented for both non-pharmacological and pharmacological treatments. The high degree of agreement with the EULAR 2000 recommendations may be explained by some attributes of these recommendations, which are clear and evidence based and may match everyday practice, thus not requiring a change of behaviour. In the light of this, it seems logical to assume that even the GPs who did not know about the EULAR 2000 recommendations were likely to prescribe the recommended treatments. This assumption was confirmed for non-pharmacological treatments, which were prescribed as often as in regular practice, regardless of whether the physicians knew of the recommendation. The prescribing of pharmacological treatments was influenced by knowledge about the EULAR 2000 recommendations, which might mean that in managing knee osteoarthritis in general practice physicians less commonly prescribe paracetamol and NSAIDs than they do non-pharmacological treatments. The choice of paracetamol rather than NSAIDs as first line therapy is controversial. ${ }^{7-11}$ Despite several trials showing that patients who received NSAIDs had greater improvement in pain or function than those receiving paracetamol, EULAR and other recommendations ${ }^{12}$ propose paracetamol as a first line treatment because of the positive long term benefit of this drug compared with classical NSAIDs. This conflicting information could in part explain physicians' preferences.

We found that compliance with the EULAR 2000 recommendations was not high but is expected to increase. This study was done quite early (about one year) after the publication of the recommendations, so data were collected before the end of the adaptation period. Increased adherence to recommendations with time has been demonstrated. ${ }^{13}$

Studies exploring adherence to the EULAR 2000 or ACR recommendations for knee osteoarthritis are rare or nonexistent. Results of a survey recently conducted in Spain showed a high level of acceptance of the EULAR 2000 recommendations for managing knee osteoarthritis, but compliance was not assessed. ${ }^{14}$ Further studies in other countries should therefore be undertaken to evaluate the implementation of EULAR recommendations for osteoarthritis.

\section{ACKNOWLEDGEMENTS}

This study was supported by Bristol-Myers Squibb.

\section{Authors' affiliations}

L Denoeud, P Ravaud, Bichat Claude Bernard Hospital, Department of Epidemiology, Biostatistics and Clinical Research, AP-HP, Paris, France B Mazières, Paul Sabatier University and Department of Rheumatology, University Hospital of Rangueil, Toulouse, France

C Payen-Champenois, Bristol-Myers Squibb, Medical Department, Rueil-Malmaison, France

\section{REFERENCES}

1 Felson DT, Naimark A, Anderson J, Kasis L, Castelli W, Meenan RF. The prevalence of knee osteoarthritis in the elderly. The Framingham Osteoarthritis Study. Arthritis Rheum 1987;30:914-18.

2 Altman R, Hochberg M, Moskovitz R, Schnitzer T. Recommendations for the medical management of osteoarthritis of the hip and knee: 2000 update. American College of Rheumatology Subcommittee on Osteoarthritis Guidelines. Arthritis Rheum 2000;43:1905-15.

3 Pendleton A, Arden N, Dougados M, Doherty M, Bannwarth B, Bijlsma JW, et al. EULAR recommendations for the management of knee osteoarthritis: report of a task force of the Standing Committee for International Clinical Studies Including Therapeutic Trials (ESCISIT). Ann Rheum Dis 2000:59:936-44.

4 Cabana M, Rand C, Powe N, Wu A, Wilson M, Abboud PA, et al. Why don't physicians follow clinical practice guidelines? (A framework for improvement). JAMA 1999;282:1458-65.

5 Altman R, Asch E, Bloch D, Bole G, Borenstein D, Brandt K, et al. Development of criteria for the classification and reporting of osteoarthritis. Classification of osteoarthritis of the knee. Diagnostic and Therapeutic Criteria Committee of the American Rheumatism Association. Arthritis Rheum 1986;29:1039-49.

6 Haynes RB, Sackett DL, Gray J, Cook D, Guyatt G. Transferring evidence from research into practice: 1 . The role of clinical care research evidence in clinical decisions. ACP J Club 1996;125:A14-16.

7 Jordan KM, Arden NK, Doherty M, Bannwarth B, Bijlsma JW, Dieppe P, et al. EULAR recommendations 2003: an evidence based approach to the management of knee osteoarthritis: report of a task force of the standing committee for international clinical studies including therapeutic trials (ESCISIT). Ann Rheum Dis 2003;62:1145-55.

8 Wegman A, Van der Windt D, Van Tulder M, Stalman W. Nonsteroidal antiinflammatory drugs or acetaminophen for osteoarthritis of the hip or knee? A systematic review of evidence at guidelines. J Rheumatol 2004;31:344-54.

9 Wegman A, Van der Windt D, de Haan M, Devillé W, Fo C, de Vries T. Switching from NSAIDs to paracetamol: a series of $n$ of 1 trials for individual patients with osteoarthritis. Ann Rheum Dis 2003;62:1156-61.

10 Pincus T, Koch G, Lei H, Mangal B, Sokka T, Moskowitz R, et al. Patient preference for placebo, acetaminophen or celecoxib efficacy studies (PACES): two randomised placebo controlled crossover clinical trials in patients with oseoarthritis of the knee or hip. Ann Rheum Dis 2004;63:931-9.

11 Zhang W, Jones A, Doherly M. Does paracetamol (acetaminophen) reduce the pain of osteoarthritis? a meta-analysis of randomised controlled trials. Ann Rheum Dis 2004;63:901-7.

12 Pham T, Framsen M, Ravaud P, Dougados M, Ottawa Methods Groups. Osteoarthritis on evidence based rheumatology. London: BMJ Publishing Group, 2003

13 Grimshaw JM, Eccles MP, Walker AE, Thomas RE. Changing physicians' behavior: what works and thoughts on getting more things to work. J Contin Educ Health Prof 2002;22:237-43.

14 De Miguel E, Martin-Mola E. EULAR recommendations for the management of knee osteoarthritis. Results of an opinion survey in Spanish physicians [abstract]. Ann Rheum Dis 2003;62(suppl 1):273. 